\title{
Composition, tensile strength, and elastic modulus of Orden as cast post alloy
}

\author{
Novi Anggraini, Zulia Hasratiningsih, Gantini Subrata \\ Department of Prosthodontics Faculty of Dentistry Universitas Padjadjaran
}

\begin{abstract}
Post is one element of the fixed restorations that is generally used to restore endodontically treated teeth at Prosthodontic Installation of Oral and Dental Hospital (RSGM) Faculty of Dentistry Universitas Padjadjaran, whereas Orden alloy is still used as cast post material. The faculty supplies Orden without packaging or manuals, so the information about its composition and mechanical properties are not available. This study was conducted to search the composition, tensile strength, and elastic modulus of Orden. For the composition test, specimen with size $20 \times 20 \times 2 \mathrm{~mm}^{3}$ was tested with Optical Emission Spectroscopy (OES). For tensile test, 6 specimens were made according to ASTM Standard E8. While for bending test, 6 specimens were made according to ASTM Standard E855. The Universal Testing Machine Instron 1195 was used to test the tensile strength and elastic modulus. The value of tensile strength of Orden was compared to gold alloy type III and the value of elastic modulus of Orden was compared to dentin. Composition test found that Orden was a brass with the largest ingredient of copper $53.76 \mathrm{wt} \%$, followed by zinc $44.94 \mathrm{wt} \%$, and alumunium $1.17 \mathrm{wt} \%$. The statistic calculation showed that tensile strength of Orden was lower than gold alloy type III and the elastic modulus of Orden was higher than dentin.
\end{abstract}

Key words: Composition, tensile strength, elastic modulus, orden.

\section{INTRODUCTION}

Post crown is one of fixed restoration which is commonly used to repair teeth that have undergone endodontic treatment. However, not all teeth that have been endodontically treated should be restored by making post crown. The use of post is an indication when the anatomic crowns have been damaged badly. ${ }^{1,2}$

In Prosthodontic Installation of RSGM Faculty of Dentistry UNPAD, clinic and preclinic students must meet the requirements for making cast post crowns on anterior teeth. The kind of metal commonly used for making cast post is Orden.
According to Martanto ${ }^{3}$, Orden is a base-metal alloy that is considered as soft metal. This metal is used because it is relatively cheap and easy to manipulate so that it is beneficial to patients and operators.

The metal used for post must have similar elastic modulus to dentin in order to evenly distribute the stress to the root, thus reducing the possibility of root fracture. ${ }^{4,5}$ The same opinion was also suggested by Akkayan ${ }^{2}$, Elias ${ }^{6}$, and MartinezInzua et al. ${ }^{7}$ They stated that the posts that have the same elastic modulus as dentin can reduce the risk of root fracture. ${ }^{2,6,7}$

There are several types of posts, based on 
the manufacturing proces, posts can be divided into prefabricated posts and cast posts. Cast post is made by dentists by making appropriate wax patterns in the root canal preparation which is then casted with metal, while prefabricated post is made by manufacturers, available in various shapes, sizes, and materials. ${ }^{3,8}$ Based on the type of the material, prefabricated post can be divided into stainless steel post, zirconium post, titanium post, and fiber post. ${ }^{8}$

The advantage of cast post is its good adaptation to the root canal walls because it is fitted to the shape of its root canal preparation. ${ }^{2,9}$ However, cast post also has a disadvantage. The failure that might occur when using a cast post is the root fracture because the cast post itself has a high resistance against fracture..$^{10,11}$ Several studies showed that a restoration with cast post can caused a high internal stress on the root. ${ }^{10}$ Martinez-Inzua et al. ${ }^{2}$ reported that the magnitude of the fracture load of cast post was higher than fiber post. ${ }^{12}$

If a structure consisting of two different materials (such as post and dentine) receives a force, the material with higher elastic modulus will be able to withstand towards larger forces without changing the shape. ${ }^{1,5,11,13}$ Posts with higher elastic modulus than that of dentin tend to cause root fracture, because the stress will be distributed and is concentrated in the roots that are less stiff. ${ }^{1,5,11}$ Posts that have lower elastic modulus than dentin tend to protect the dentin from fracture..$^{9,13}$

Strength is also very important in post metal selection, this correspond to post diameter..$^{1,5,8,14}$ Material's strength can be measured by the tensile strength, that is the material's ability to withstand a maximum tensile stress before fracture. ${ }^{15-17}$ Cast post is made in small diameter, not more than $1 / 3$ of root diameter. ${ }^{3}$ With such a small diameter, the post must be able to withstand the chewing force..$^{1,14}$ For reference, the strength of Orden can be compared to gold alloy type III which is commonly used for posts based on the specifications of American Dental Association (ADA) No. $5 .{ }^{18}$

Orden used in Prosthodontic Installation of Oral and Dental Hospital (RSGM) Faculty of Dentistry Universitas Padjadjaran does not come with packaging and brochures, so the information about the composition of this metal cannot be obtained. Whereas, the composition of a material greatly affects its mechanical properties including its tensile strength and elastic modulus. ${ }^{17}$ Due to the facts, the author is interested in studying the composition, tensile strength and elastic modulus of Orden in order to get information to consider the selection of this metal for a cast post.

\section{MATERIALS AND METHODS}

The research method used for composition test is a descriptive study. As for testing tensile strength and elastic modulus, pre-experimental research, called the one-shot case study was used. ${ }^{19}$ Data of tensile strength test results and the elastic modulus were analyzed with $t$ test.

This research was conducted in the Prosthodontic Installation of Faculty of Dentistry, Universitas Padjadjaran, Laboratory of Metallurgy of Ministry of National Education Polytechnic of Manufacture Bandung, and Metallurgy Laboratory of Institut Teknologi Bandung. The research was conducted in November 2007 to March 2008.

The population of the research was Orden alloy supplied by Faculty of Dentistry of Universitas Padjadjaran. The samples were drawn randomly from the population according to the number needed to make research specimens.

This study used the specimens as follows: For composition test, one piece of metal specimen size $20 \times 20 \times 2 \mathrm{~mm}^{3}$ (Fig.1a); For tensile strength test (tensile test), 6 pieces of metal specimens with the shape and size in accordance with ASTM standard E8 (Fig. 1b). ${ }^{20}$ For elastic modulus test (bending test), 6 pieces of metal specimens size $80 \times 13 \times 0,6 \mathrm{~mm}^{3}$ in ASTM standard E855 (Fig. 1c). ${ }^{21}$

The research procedure consisted of the manufacturing procedure for the test specimen and the testing procedure. The test specimen's production was using the "lost wax technique" casting method. The test procedures consisted of the composition test, tensile strength test and bending test. For the composition test procedure, the test specimen is inserted into the Optical Emission Spectroscopy (Fig. 2), and then it was shot with photon ray at 3 different points locations. Test results could be viewed at the computer print out. For tensile strength test procedure, calculate the width and thickness of each tensile test 


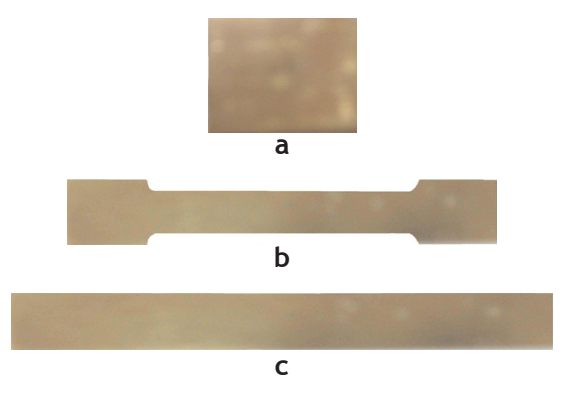

Figure 1. Test specimens.

Description: (a) the composition test specimen, (b) tensile test specimens, (c) bending test specimens.

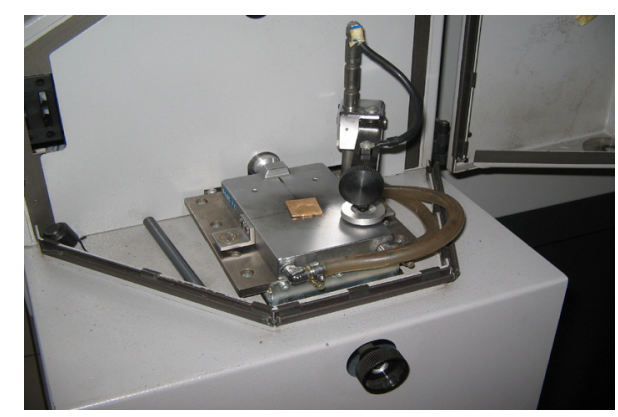

Figure 2. Specimen placement on Optical Emission Spectroscopy (OES).

specimen to determine cross-sectional area. The specimen was placed on the test machine (Fig. 3), then was pulled with the speed of $1 \mathrm{~mm} /$ minute (Metallurgy Laboratory ITB). The results could be viewed on the computer in the form of load curve $(\mathrm{kg})$ to the length elongation $(\mathrm{mm})$. Perform data processing, the load curve to the elongation was processed into stress-strain curve. Tensile strength was determined from stress-strain curve by observing the maximum stress before the specimen fractured.

For the bending test procedure, calculate the width and thickness of each bending test specimen. The specimen was placed on the test machine (Fig. 4), then compressed at the speed of $0.5 \mathrm{~mm} / \mathrm{min}$ (Laboratory of Metallurgy ITB). The results could be viewed on a computer in the form of load curve $(\mathrm{kg})$ to the deflection $(\mathrm{mm})$. Elastic modulus was determined using the following formula:

\section{$E=\underline{L}^{3} \underline{\Delta P}$}

$4 \mathrm{bh}^{3} \Delta \delta$

Where: $L=$ length of the specimen $(\mathrm{mm})$

$\mathrm{P}=$ force $(\mathrm{N})$

$\mathrm{b}=$ width of the specimen $(\mathrm{mm})$

$\mathrm{h}=$ thickness of the specimen $(\mathrm{mm})$

$\delta=$ deflection $(\mathrm{mm})$

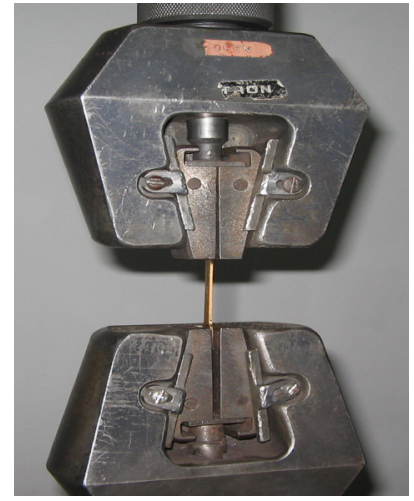

Figure 3. Tensile strength test using Universal Testing Machine Instron 1195.

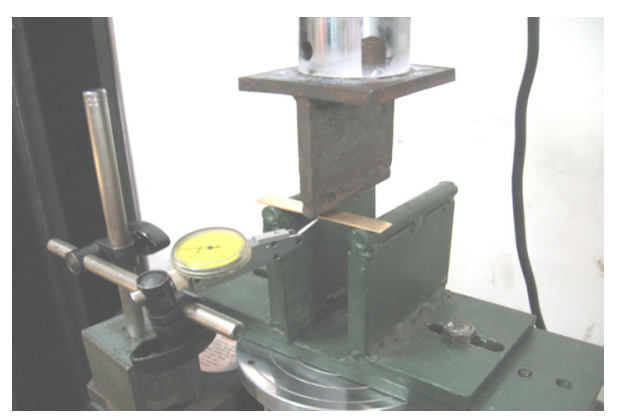

Figure 4. Bending test using Universal Testing Machine instron 1195.

When the tensile strength and elastic modulus datas have been obtained, the average value and the standard deviation were determined. Then by using the $t$ test, the tensile strength of orden was compared to the tensile strength of gold alloy type III, whereas the elastic modulus was compared to the elastic modulus of dentin.

\section{RESULTS}

Based on the spectroscopy test result (Table 1), it was found that Orden was a copper-zincaluminum (Cu-Zn-Al) alloy. The composition of the alloy was primarily copper and zinc, which was known as brass. ${ }^{22-24}$

The tensile strength of Orden was presented at Table 2. Based on Table 2 the average value of the tensile strength of Orden was $300.6632 \mathrm{MPa}$. The average value of the tensile strength of Orden was then compared to the tensile strength of gold alloy type III which was $448 \mathrm{MPa} .{ }^{25}$ The test was done using $t$ test one sample. it was found that the tensile strength of orden was lower than the tensile strength of gold alloy type III. 
Table 1. Orden composition based on the spectroscopy test results.

\begin{tabular}{ll}
\hline \multicolumn{1}{c}{ Element } & \multicolumn{1}{c}{ (wt\%) } \\
\hline Copper (Cu) & 53.75722 \\
Zinc ( $\mathrm{Zn})$ & 44.94236 \\
Alumunium (Al) & 1.17443 \\
Nickel (Ni) & 0.04805 \\
Iron (Fe) & 0.03199 \\
Silicon (Si) & 0.02074 \\
Lead (Pb) & 0.01233 \\
Antimony (Sb) & 0.01028 \\
Sulfur (S) & 0.00189 \\
Phosphorus (P) & 0.00120 \\
Magnesium (Mg) & 0.00118 \\
\hline
\end{tabular}

Table 2. Orden tensile strength test results and Orden bending test results.

\begin{tabular}{ccc}
\hline Specimen & $\begin{array}{c}\text { Tensile strength } \\
(\mathrm{MPa})\end{array}$ & $\begin{array}{c}\text { Elastic modulus } \\
(\mathrm{GPa})\end{array}$ \\
\hline 1 & 323.0257 & 76.9740 \\
2 & 278.6705 & 82.6996 \\
3 & 269.7160 & 79.7765 \\
4 & 305.7680 & 85.7826 \\
5 & 301.0639 & 79.8550 \\
6 & 325.7349 & 76.2919 \\
\hline Average & 300.6632 & 80.2299 \\
\hline
\end{tabular}

Based on the bending test data processing results the elastic modulus of orden was presented at Table 2. Based on Table 2, the average value of elastic modulus was $80.2299 \mathrm{GPa}$. The average value of the elastic modulus of orden was compared to the elastic modulus dentin, which $17 \mathrm{GPa} .{ }^{21}$ The test was conducted using the test one sample and it was found that the elastic modulus of orden was higher than dentin. It means orden cast post was stiffer than dentin.

\section{DISCUSSION}

Copper is a ductile and maleable metal. ${ }^{17,23,24}$ The addition of zinc increases the strength and zinc serves also as a deoxidizing agent that will prevent corrosion. ${ }^{16,17,22}$ Nickel increases the strength, hardness, and resistance to abrasion and corrosion. ${ }^{15,17,23}$ Aluminum (Al) increases the strength and resistance to corrosion. ${ }^{17,24}$

Silicon ( $\mathrm{Si}$ ) increases the strength, hardness, resistance to corrosion, increases fluidity, and castability. ${ }^{17,22}$ Lead $(\mathrm{Pb})$ increases the machinability. ${ }^{23}$ Phosphorus $(\mathrm{P})$ serves to prevent corrosion and increase the fluidity of the alloy so that it facilitates the process of casting. ${ }^{23-24}$ Magnesium $(\mathrm{Mg})$ increases the fluidity and castability. ${ }^{17}$

Pure copper has a tensile strength of 200 $\mathrm{MPa} .^{22}$ From the results of this study; the tensile strength of orden was $300.66 \mathrm{MPa}$. Based on these data, it can be concluded that addition of other metals can improve the tensile strength of copper. This is in line with some theories that explain the influence of the addition of other metals to copper. According to Johnson, the mixture of zinc and copper up to $45 \mathrm{wt} \%$ will increase the tensile strength. ${ }^{23}$ In addition; the strength of copper will be increased with the addition of aluminum, nickel, iron, and silicon. ${ }^{17,22-23}$

One of the requirement for post metal alloy is that it should be made in the minimum diameter. It will be possible if the alloy has a high strength so that it will be strong enough to resist chewing forces. ${ }^{1,9,14}$ The higher the strength of the post, the smaller the diameter it can be mode. ${ }^{8}$ Based on the result of statistical analysis, it was known that orden has a lower tensile strength than gold alloy type III. However, the usege of Orden as a cast post on the anterior teeth can still be considered if it is made with maximum root diameter of $1 / 3$. To develop orden alloy, further research on the addition of other metals that can increase tensile strength needs to be conducted so that the tensile strength of orden can be similar to the gold alloy.

Pure copper has elastic modulus of 110 $\mathrm{GPa} .{ }^{26}$ While the results of this research noted that elastic modulus of orden was $80.22 \mathrm{GPa}$. Based on the data, besides increasing the tensile strength, the addition of other metals to copper can also reduce the elastic modulus. However, based on the result of statistical analysis the elastic modulus of orden was still higher than that of dentin. Further research on addition of other metals which can reduce the elastic modulus of orden to be closer to dentin needs to be conducted. Thus, Orden can be more qualified to be used as post metal in terms of the modulus of elasticity.

The ideal post alloy should have similar elastic modulus to dentin in order to properly distribute the stress to the root, thus reducing the risk of root fracture..$^{2,4-6,12}$ Based on this study, Orden has a higher elastic modulus than of dentin. 
Post with higher elastic modulus tends to cause root fracture because the strees will be distributed and is concentrated in the less stiff roots compared to the post, this should be avoided in the usage of a post. ${ }^{1,5,11}$

\section{CONCLUSION}

The conclusions drawn from this study are as follows: Orden is the alloy of $\mathrm{Cu}-\mathrm{Zn}-\mathrm{Al}$; Orden has a tensile strength of $300.66 \mathrm{Mpa}$; Orden has a lower tensile strength than gold alloy type III; Orden has elastic modulus of $80.22 \mathrm{GPa}$; Orden has a higher elastic modulus than that of dentin.

\section{REFERENCES}

1. Cohen S, Hargreaves KM. Pathways of the pulp. $9^{\text {th }}$ ed. Missouri: Mosby; 2006. p. 794-802.

2. Elias S. Restorasi mahkota pasak menggunakan fiber-post untuk meningkatkan nilai estetik pasien. Proceeding: Pertemuan IImiah IImu Kedokteran Gigi IPROSI 2007. p. 105-8.

3. Martanto P. Teori dan praktek ilmu mahkota dan jembatan (fixed partial prosthodontics). Bandung: Penerbit Alumni; 1985. p. 141-61, 163-204,212-8.

4. Newman MP, Yaman P, Dennison J, Rafter M, Billy $E$. Fracture resistance of endodontically treated teeth restored with composite post. J Prosthet Dent 2003;89:360-7.

5. Walton RE, Torabinejad M. Principles and practice of endodontics. $3^{\text {rd }}$ ed. Philadelphia: Saunders Co.; 2002. p. 268-80.

6. Akkayan B, Dent M, Gulmez T. Resistance to fracture of endodontically treated teeth with different post system. J Prosthet Dent 2002;87:431-7.

7. Martinez-Inzua A, da Silva L, Rilo B, Santana $U$. Comparison of the fracture resistances of pulpless teeth restored with a cast post and core or carbon fiber post with a composite core. J Prosthet Dent 1998;80:527-32.

8. Schwartz RS, Robbins JW. Post placement and restoration of endodontically treated teeth: $A$ literature review. J Endod 2004;30:289-99.

9. Weine FS. Endodontic therapy. $6^{\text {th }}$ ed. St. Louis: Mosby; 2004. p. 546-62.

10. Pereira JR, Ornelas, Fabio. Effect of a crown ferrule on the fracture resistance of endodontically treated teeth restored with prefabricatedpost. JProsthetDent 1995;1:50-4.

11. Pilo R, Cardash HS, Levin E, Assif D. Effect of core stiffness on the in vitro fracture of crowned, endodontically treated teeth. J Prosthet Dent 2002;88:302-6.

12. Martinez-Inzua A, da Silva L, Rilo B, Santana $U$. Comparison of the fracture resistances of pulpless teeth restored with a cast post and core or carbon fiber post with a composite core. J Prosthet Dent 1998;80:527-32.

13. Assif D, Bitenski A, Pilo R, Oren E. Effect of post design on resistance to fracture of endodontically treated teeth with complete crown. J Prosthet Dent 1993;69:36-40.

14. Stock CJR, Gulabivala K, Walker RT. Endodontics. $3^{\text {rd }}$ ed. Edinburgh: Mosby; 2004. p. 279-96.

15. Anusavice KJ. Phillips' science of dental materials. $11^{\text {th }}$ ed. St Louis: Saunders Co.; 2003. p. 30-2,73-100,103-16,295-334,563-80.

16. Craig RG, Powers JM, Wataha JC. Dental materials properties and manipulation. $8^{\text {th }}$ ed. St. Louis: Mosby; 2004. p. 21-8,234-43,25567.

17. Powers JM, Sakaguchi RL. Craig's restorative dental materials. $12^{\text {th }}$ ed. St Louis: Mosby; 2006. p. 51-65,131-45,313-32,347-9,359-73, 386-92,411-25.

18. American Dental Association. Guide to dental materials and device. $7^{\text {th }}$ ed. Chicago: American Dental Association; 1974. p. 209-11.

19. Notoatmodjo S. Metodologi penelitian kesehatan. Jakarta: Rineka Cipta; 2002. p. 13844,156-69.

20. Copper and copper alloys (including electrical conductors). Part 6 Philadelphia: Annual book of American Society for Testing and Materials Standards; 1981. p. 1047-58

21. Metals test methods and analytical prosedures. Philadelphia: Annual Book of American Society for Testing and Materials Standards; 2000. p. 4-7.

22. Budinski KG, Budinski MK. Engineering materials properties and selection. $6^{\text {th }}$ ed. New Jersey: Prentice Hall; 1999. p. 31-6,521-44.

23. Johnson CG. Metallurgy. $4^{\text {th }}$ ed. Chicago: American Technical Society; 1983. p. 194214.

24. Nayak SP. Engineering metallurgy. Tulsi Sadan: 
Charotar Book Stall; 1970. p. 368-81.

25. O'Brien WJ. Dental materials and their selection. $3^{\text {rd }}$ ed. Chicago: Quintessence Publishing Co, Inc.; 2002. p. 326-72
26. Callister WD. Fundamentals of materials science and engineering. $5^{\text {th }}$ ed. New York: John Willey \& Sons Inc; 2001. p.147-71. 